\title{
Pemberdayaan Perempuan Melalui Keluarga Tangguh Kelompok Tani Wanita Di Masa Pandemi Covid-19
}

\author{
Dyah Mutiarin 1*, Adhianty Nurjannah ${ }^{2}$, Dianita Sugiyo3, Sakir ${ }^{4}$ \\ 1. Magister Ilmu Pemerintahan, Program Pasca Sarjana, Universitas Muhammadiyah Yogyakarta \\ ${ }^{2}$ IImu Komunikasi, Fakultas IImu Sosial dan Ilmu Politik, Universitas Muhammadiyah Yogyakarta \\ ${ }^{3}$ Program Studi Keperawatan, Fakultas Kedokteran dan Ilmu Kesehatan, Universitas Muhammadiyah Yogyakarta \\ ${ }^{4}$ Ilmu Pemerintahan, Fakultas Ilmu Sosial dan Ilmu Politik, Universitas Muhammadiyah Yogyakarta \\ Universitas Muhammadiyah Yogyakarta - Kampus Terpadu UMY-Jl. Brawijaya, Kasihan, Bantul - Yogyakarta, 55183, 0274387656 \\ Email: dyahmutiarin@umy.ac.id \\ DOI: $10.18196 / p p m .34 .296$
}

\begin{abstract}
Abstrak
Pemberdayaan perempuan melalui keluarga tangguh di masa pandemi covid-19 menjadi kebutuhan bagi tiap keluarga untuk mengantisipasi dampak covid-19 yang semakin meluas. Tulisan ini fokus pada keluarga tangguh, karena keluarga menjadi benteng pertahanan yang paling dasar untuk melawan covid-19. Berdasar problem dampak covid-19 pada berbagai aspek seperti kesehatan, ekonomi, social dan Pendidikan, maka pemberdayaan perempuan melalui keluarga tangguh dilakukan di desa Trimulyo, Bantul, Yogyakarta. Metode yang dilakukan adalah dengan melakukan penyadaran, sosialisasi, peningkatan pengetahuan dan melatih ibu-ibu untuk bercocok tanam tanaman sayuran di lahan rumah masing-masing untuk menekan dampak ekonomi karena covid-19. Hasil yang diperoleh adalah meningkatnya kesadaran, pengetahuan dan terbentuknya komunitas keluarga tangguh melawan covid-19.
\end{abstract}

Keywords: Pemberdayaan Perempuan, Keluarga Tangguh, dampak Covid-19.

\section{Pendahuluan}

Pemberdayaan perempuan melalui keluarga tangguh di masa pandemi covid-19 menjadi kebutuhan bagi tiap keluarga untuk mengantisipasi dampak covid-19 yang semakin meluas. Paper ini fokus pada keluarga tangguh, karena keluarga menjadi benteng pertahanan yang paling dasar untuk melawan covid-19.

Angka kemiskinan di Desa Trimurti masih cukup tinggi, ada sebanyak 670 (enam ratus tujuh puluh) KK. Sedangkan pada tahun 2017 angka kemiskinan Desa Trimurti sebesar 651 (enam ratus enam puluh lima) KK. Memang ada penurunan dari tahun sebelumnya namun masih sangat jauh dari kata baik. (LPPDes, 2017). Permasalahan kemiskinan di pedesaan juga disebabkan pembangunan yang cenderung kurang merata pada bidang pendidikan. (Setiawati, 2013).

Desa merupakan entitas pemerintahan terkecil dengan dinamika yang sangat cepat. Dalam UU No 6 Tahun 2014 pasal 4 tercantum pengaturan tentang Desa salah satunya adalah untuk mendorong prakarsa, gerakan, dan partisipasi masyarakat desa untuk pengembangan potensi dan aset desa guna kesejahteraan bersama. Oleh karena itu pemberdayaan perempuan di Desa sesuai dengan amanat UU no 6 Tahun 2014. Pemberdayaan perempuan di pedesaan merupakan salah satu upaya untuk menghapuskan kesenjangan. Salah satunya dengan Kelompok Wanita Tani (KWT) Lestari, namun sayangnya KWT Lestari di Dusun Puluhan Lor Desa Trimurti belum berjalan dengan baik, permasalahan seperti masih rendahnya partisipasi masyarakat dan minimnya pengetahuan menjadi masalah utama. Minimnya akses untuk pengembangan potensi yang dimiliki, belum optimalnya keterlibatan kaum perempuan dalam kegiatan yang ada, masih rendahnya keterampilan khusus dalam memanfaatkan sumber daya yang ada di pedesaan juga masih dialamai oleh anggota KWT. Permasalahan Kelompok Wanita Tani dapat ditangani dengan pemberdayaan dan pendampingan yang benar serta secara komprehensif 
Berdasar problem dampak covid-19 pada berbagai aspek seperti kesehatan, ekonomi, social dan Pendidikan, maka pemberdayaan perempuan melalui keluarga tangguh dilakukan di desa Trimulyo-Bantul-Yogyakarta. Tujuan umum program pemberdayaan ini adalah untuk meningkatkan pengetahuan dan keterampilan para anggota KWT dalam membentuk kecintaan terhadap tanaman sayur, memanfaatkan sumberdaya pedesaan dalam pemberdayaan perempuan terutama di masa pandemic Covid-19 ini. Target dari Program KKN-PPM ini adalah terbentuknya Kelompok Wanita Tani yang memiliki pengetahuan dan keterampilan, serta mampu memanfaatkan sumberdaya desa yang dimiliki.

\section{Metode Pelaksanaan}

Proses pemberdayaan masyarakat (Mutiarin, 2017) bertujuan: 1). Agar masyarakat mampu mengidentifikasi dan menganalisis permasalahannya sendiri, 2). Memfasilitasi agar masyarakat mampu merumuskan beberapa alternatif pemecahan masalahnya, 3). Mendorong masyarakat agar mampu menggali potensinya sekaligus mengembangkannya. Memberdayakan masyarakat bertujuan "mendidik masyarakat agar mampu mendidik diri mereka sendiri" (Korten, 2002). Pemberdayaan Kelompok Wani Tani dilakukan melalui pembentukan keluarga cinta tenaman sayur di Dusun Puluhan Lor Desa Trimurti Kecamatan Srandakan Kabupaten Bantul. Melalui pemberdayaan dan dan pendampingan Dusun Puluhan Lor diiharapkan memiliki kelompok wanita tani yang lebih baik. Kegiatan tersebut berdasarkan hasil observasi tentang kondisi nyata oleh tim pengusul.

Berikut tahapan pelaksanaan program kegiatan sebagai berikut:

1. Peningkatan Pengetahuan dan Keterampilan KWT Lestari

a. Survei identifikasi masalah pada keluarga KWT Dusun Puluhan Lor

b. Pengenalan konsep keluarga tangguh melalui KWT

c. Penyiapan logistik dan perangkat peraga edukasi keluarga tangguh

2. Pendampingan kepada kelompok sasaran KWT Lestari

a. Sosialisasi tentang pengelolan keluarga tangguh KWT untuk menanam tanaman sayur

b. Pelatihan implementasi keluarga tangguh menjadikan produk dari hasil tani sebagai olahan yang bernilai ekonomis

3. Pemberdayaan kelompok sasaran KWT Lestari

Edukasi dan advokasi kepada masyarakat mengenai pentingnya kelompok Wanita Tani di Desa.

\section{Hasil dan Pembahasan}

Ekowati (2014) dalam studinya juga menyampaikan bahwa, masyarakat memiliki banyak pengalaman, tekun, ulet, kreatif inovatif dan juga memiliki kemampuan mengelola untuk menjaga keberlangsungan kehidupan keluarga dan komunitasnya. Dalam hal ini pelaksanaan pemberdayaan secara teori dengan hipotesis Ekowati tersebut. Pelaksanaan pemberdayaan keluarga tangguh melalui KWT di masa pandemic covid-19 ini dilakukan di Desa Trimurti Kecamatan Srandakan, Kabupaten Bantul, Yogyakarta. Desa Trimurti sendiri terdiri dari 20 dusun salah satunya adalah Dusun Puluhan Lor.

\section{Survey identifikasi masalah pada keluarga KWT Lestari Dusun Puluhan Lor}

Untuk mengidentifikasi permasalahan-permasalahan yang ada yaitu melalui kegiatan survey menemukenali persoalan-persoalan pada keluarga KWT Dusun Puluhan Lor.

2. Keluaran (output) dari kegiatan tersebut adalah adanya pemetaan berbagai permasalahan 
yang terjadi pada KWT.

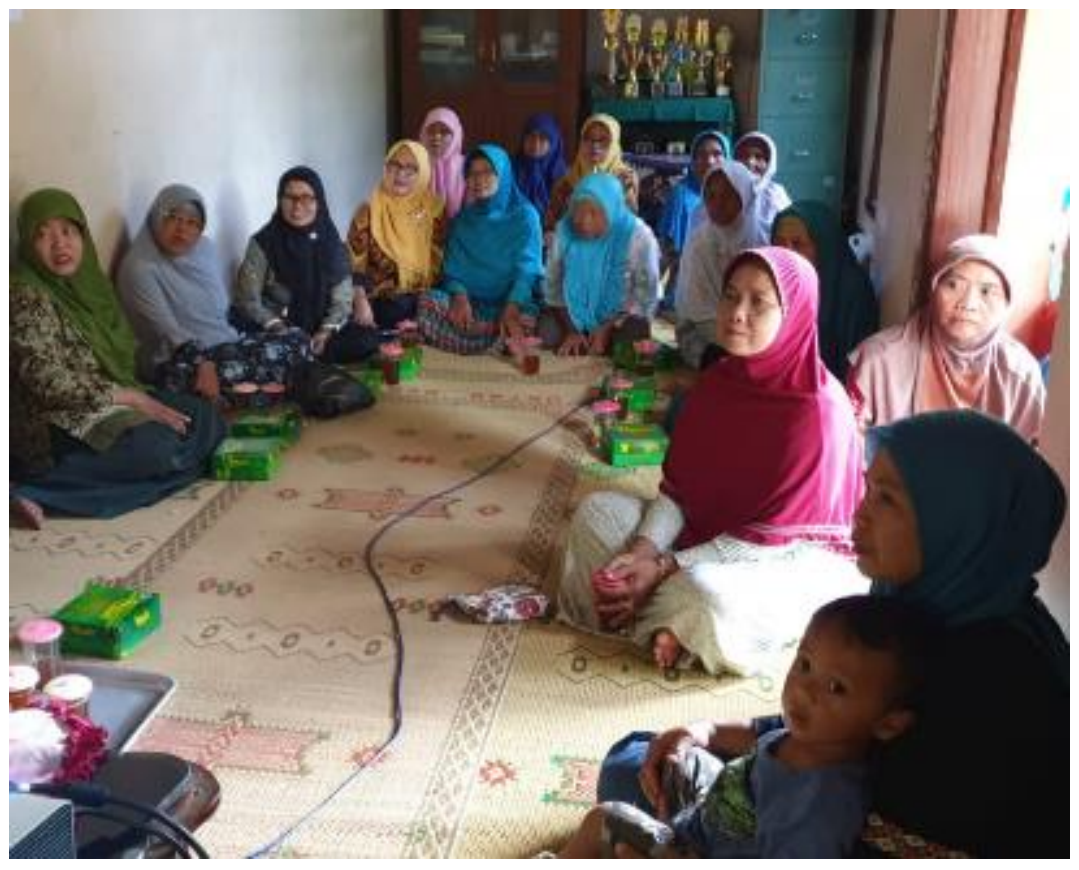

Survey keluarga tangguh KWT (dokumen pribadi, 2019)

Maka survey ini kemudian menghasilkan pemetaan masalah keluarga tangguh KWT dalam masa pandemic covid-19.

Tabel 1. Identifikasi Masalah Budaya Keluarga

\begin{tabular}{|l|l|l|}
\hline $\begin{array}{l}\text { Jumlah } \\
\text { keluarga }\end{array}$ & Identifikasi Masalah Budaya Keluarga & Tujuan yang belum tercapai \\
\hline $10 \mathrm{KK}$ & Anggota keluarga belum terlibat dalam kegiatan KWT & Peningkatan pendapatan \\
\hline $5 \mathrm{KK}$ & $\begin{array}{l}\text { Anggota keluarga belum bersedia dan rutin menanami lahan } \\
\text { pekarangan }\end{array}$ & Pemenuhan kebutuhan keluarga \\
\hline $7 \mathrm{KK}$ & $\begin{array}{l}\text { Anggota keluarga belum terlibat dalam meningkatkan sediaan } \\
\text { sayuran untuk konsumsi sayuran keluarga }\end{array}$ & Pemanfaatan lahan pekarangan \\
\hline $6 \mathrm{KK}$ & Anggota keluarga belum sepakat menanam sayuran & Budaya konsumsi sayuran \\
\hline
\end{tabular}

\section{Peningkatan Pengetahuan, Keterampilan dan membentuk Budaya Keluarga} Tangguh

Dalam rangka meningkatkan pengetahuan, keterampilan dan membentuk Budaya Keluarga Tangguh, peran KWT sangat signifikan. Para anggota KWT Lestari mengikuti kegiatan pelatihan yang intensif budaya keluarga tangguh, pengetahuan mengatasi dampak ekonomi covid-19, dan pentingnya menanam tanaman sayuran. Luaran dari program ini adalah terbentuknya keluarga tangguh KWT di masa pandemic covid-19.

Tabel 2. Pelatihan yang dilakukan

\begin{tabular}{|l|l|}
\hline No. & Pelatihan \\
\hline 1 & Strategi mengatasi dampak ekonomi covid-19 melalui KWT \\
\hline 2 & Pemanfaatan lahan pekarangan untuk tanaman sayuran \\
\hline 3 & Membentuk budaya keluarga tangguh \\
\hline
\end{tabular}




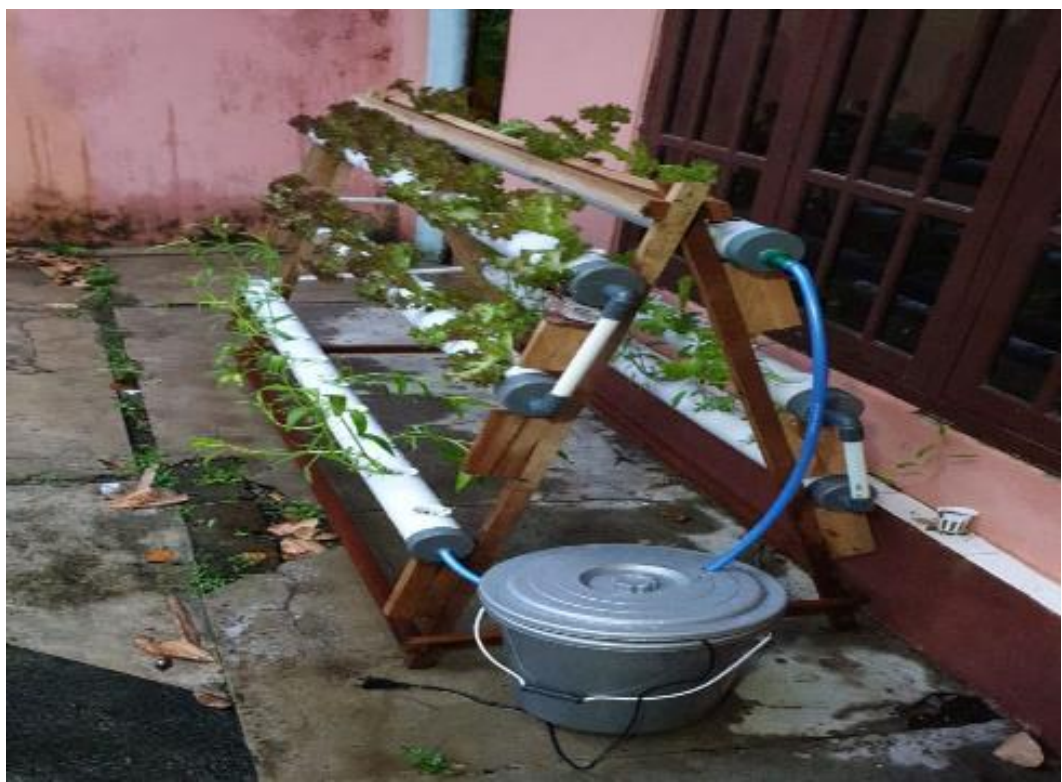

Perangkat hidroponik KWT (Sumber: dokumen pribadi, 20190

\section{Pendampingan kepada kelompok sasaran}

Tim pemberdayaan melakukan pelatihan dan pendampingan secara intensif kepada kelompok sasaran yaitu KWT Lestari, sehingga program-program yang sudah disepakati dapat terlaksana dengan baik dan target luaran dapat tercapai.

Tabel 3. Pelatihan yang dilakukan dan hasilnya

\begin{tabular}{|l|l|l|l|}
\hline $\begin{array}{l}\text { Jumlah } \\
\text { Peserta }\end{array}$ & Pelatihan & Frekuensi & Hasil \\
\hline $27 \mathrm{KK}$ & $\begin{array}{l}\text { Strategi mengatasi dampak ekonomi covid-19 melalui } \\
\text { KWT }\end{array}$ & 1 kali & $80 \%$ \\
\hline $20 \mathrm{KK}$ & Pemanfaatan lahan pekarangan untuk tanaman sayuran & 2 kali & $85 \%$ \\
\hline $25 \mathrm{KK}$ & Membentuk budaya keluarga tangguh & $1 \mathrm{kali}$ & $90 \%$ \\
\hline
\end{tabular}

\section{Pemberdayaan kelompok sasaran}

Kelompok sasaran yaitu KWT dapat menjalankan pelatihan-pelatihan yang sudah diberikan untuk membentuk keluarga tangguh. Sehingga akan tercapai keluaran yaitu kelompok sasaran sudah dapat mengaplikasikan/menerapkan pengetahuan dan keterampilan yang sudah didapat selama dilakukan pendampingan secara intensif oleh tim pengusul. Pemberdayaan tersebut meliputi aspek-aspek sbb:

Tabel 4. Aspek pemberdayaan dan hasil pemberdayaan

\begin{tabular}{|l|l|}
\hline ASPEK & HASIL \\
\hline $\begin{array}{l}\text { Kebaruan/Inovasi/ } \\
\text { Solusi yang dilakukan }\end{array}$ & Budaya keluarga tangguh KWT Lestari telah muncul \\
\hline Program yang dilaksanakan & $\begin{array}{l}\text { Ada perubahan persepsi, motivasi dan implementasi program pada anggota } \\
\text { KWT Lestari }\end{array}$ \\
\hline $\begin{array}{l}\text { Perubahan yang dicapai oleh KWT } \\
\text { Lestari }\end{array}$ & Mencapai budaya keluarga tangguh sesuai kesepakatan \\
\hline Dampak pada KWT Lestari & $\begin{array}{l}\text { Meningkatkan sikap dan perilaku perlunya memanfaatkan lahan, } \\
\text { menyiapkan kebutuhan sayuran bagi keluarga sendiri, meningkatkan } \\
\text { pendapatan keluarga melalui kegiatan KWT }\end{array}$ \\
\hline
\end{tabular}




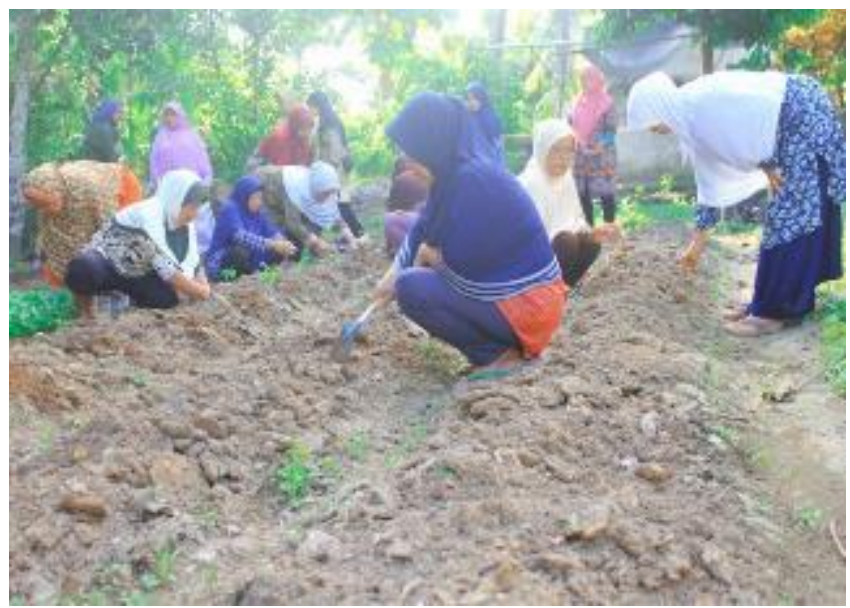

Kegiatan KWT Lestari dalam pelatihan dan pendampingan (Sumber: dokumen KKN Kelompok 12 UMY, 2019)

\section{Simpulan}

Target yang diharapkan dari program pengabdian masyarakat Pemberdayaan Perempuan Melalui Keluarga Tangguh Kelompok Tani Wanita Di Masa Pandemi Covid-19 ini adalah berupa terbentuknya keluarga tangguh KWT dan meningkatnya kemampuan bertahan dalam masa pandemic covid-19.

Selanjutnya program mampu membentuk budaya keluarga tangguh KWT. Program Mengidentifikasi permasalahan KWT Lestari untuk :

a) Peningkatan Pengetahuan dan Keterampilan KWT Lestari

b) Pendampingan kepada kelompok sasaran KWT Lestari

c) Pemberdayaan kelompok sasaran KWT Lestari

\section{Ucapan Terima Kasih}

Penulis mengucapkan terimakasih kepada :

1. LP3M UMY dengan SK No. 031/PEN-LP3M/I/2020

2. KWT Lestari

3. Bapak Dukuh Puluhan Lor

4. Mahasiswa KKN UMY kelompok 12 tahun 2019

\section{Daftar Pustaka}

Dyah Mutiarin, Sakir Sakir, Titik Sunarti Widyaningsih. 2017. Peningkatan Daya Saing TK ABA Berbasis Penguatan Organisasi dan Teknologi Informasi Melalui Program Sister School, Jurnal Berdikari, Vol 5, No 2 (2017), halaman 116-125

Ekowati, Maria Atik Sunarti . 2014. Alternatif Pemberdayaan Masyarakat Melalui Pendidikan Nonformal Dan Formal (Paud Dan TK Di Dinas Disdikpora Kota Surakarta, Seminar Nasional Dan Call For Papers UNIBA 2014

http://download.portalgaruda.org/article.php?article=269983\&val=6050\&title=ALTERNATIF\% 20PEMBERDAYAAN\%20MASYARAKAT\%20MELALUI\%20PENDIDIKAN\%20NON FORMAL\%20DAN\%20FORMAL\%20(PAUD\%20Dan\%20TK\%20di\%20Dinas\%20Dkspo ra\%20Kota\%20Surakarta)

Korten, D. C. 2002. Menuju Abad Ke-21; Tindakan Sukarela dan Agenda Global. Jakarta: Yayasan Pustaka Obor Indonesia. 
Setiawati, R. 2013. Pemberdayaan masyarakat melalui Kelompok Wanita Tani (KWT) "Seruni" berbasis Sumber Daya Lokal Di Dusun Gamelan Sendangtirto Berbah Sleman. Skripsi, Fakultas Ilmu Pendidikan Universitas Negeri Yogyakarta.

Undang-Undang Nomor 6 Tahun 2014 Tentang Desa 